\title{
Analysis of African e-commerce environment and suggestions on investment of Chinese enterprises
}

\author{
Chi $\mathrm{JIA}^{1,2, \text { a }}$ \\ ${ }^{1}$ Faculty of Humanities and Social Sciences, Memorial University of Newfoundland \\ 230 Elizabeth Avenue, St. John's, NL, Canada A1C 5S7 \\ ${ }^{2}$ School of Economics, Zhejiang Gongshang University, Hangzhou 310018, China \\ aemail: chi_jia2017@163.com
}

\section{Keywords: cross-border; e-commerce; Africa}

\begin{abstract}
With the rapid development of online economy, cross-border e-commerce has become a hot spot for scholars and investors. Due to the weakness of international trade, the opportunity for developing cross-border e-commerce is coming. Africa is an ideal capacity to undertake, with high return on investment and preferential policies of the host country, attracting the investment of crossborder e-commerce in China. This paper mainly analyze African e-commerce environment and to put forward policy recommendations of government and enterprise level.
\end{abstract}

\section{Introduction}

In recent years, the international trade market has entered into a weak stage, since the growth rate of the traditional foreign trade between China and the old developed countries, together with that of China GDP shows a downward trend. Starting from 2015, "Internet + ","One Belt and One Road"and other state strategies are frequently mentioned [1-2]. At present, the State Council is committed to expanding pilot cities of cross-border electricity business, and has introduced a number of guidance, in line with the principle of fair competition to assist enterprises to develop foreign market and business. Alibaba's AliExpress, Jingdong's Worldwide, Netease's koala and other cross-border import and export platform are flourishing.

It is well-known that China and Africa have always relatively good political and economic relations. Especially in the financial crisis, the trade volume between China and Europe and the United States and other countries declined, while that between China and Africa increased. According to China Customs statistics in 2014, China's exports to Africa grew $14.4 \%$ over the previous year, the fastest growing in all continents. Africa has vast territory and market, but because of the undeveloped industry and infrastructure, limited production capacity, the demand for highvalue manufacturing goods is very large. In recent years, since the introduction of network construction and service system in Africa, the rapid development of e-commerce in Africa, online shopping sales are expected to account for more than one-tenth of the retail industry in 2025. However, many problems in reality can not be underestimated, such as the completely different consumer culture concept of African people, imperfect infrastructure and logistics and transport networks and so on, which need to be overcome by Chinese enterprises. Therefore, this paper will 
mainly analyze African e-commerce environment in order to give suggestions on how China's cross-border electric business in Africa takes good choice and seeks to share.

\section{Growth history of China cross - border electricity business}

Cross-border e-commerce or Cross-border e-commerce electricity business refers to international business activities such as payment and trade settlement and other cross-border trade behavior through the network platform instead of trade subject in the different customs. Since cross-border B2B and B2C have obvious advantages of more direct information exchange, more accurate product positioning, which closely linked China's cross-border electricity business enterprises with retail terminals, reduced significantly the loss of intermediate channels, combined with China's production and processing strengths, enhanced the quality of products, greatly promoted the costeffective of products, accessed a higher market rate of return, maked up for China's low-profit processing.

Fig. 1 shows the proportion of cross - border e - commerce accounts for the total amount of imports and exports trade volume in recent years. According to the Fig. 1, since 2015 the deterioration of the international trade environment and trade barriers and other factors lead to the decreased import and export trade volume, but the cross-border electricity business transactions grew steadily, and their accounting for the proportion of imports and exports are gradually increasing, showing the golden age of cross-border electricity business.

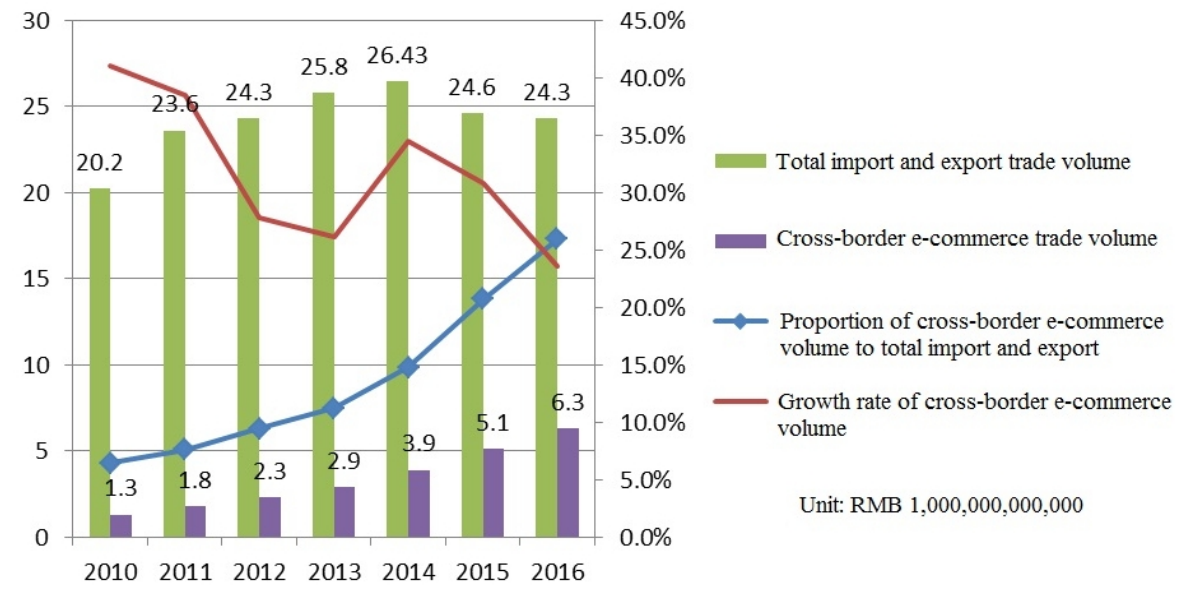

Fig 1. Cross-border e-commerce volume of China in 2010-2017

Data source: General Administration of Customs and National Bureau of Statistics

\section{Analysis on African e-commerce environment}

Political background. As the world's last regime independent region, most of the African countries have stabilized the regime, reduced the war. In order to better develop the economy, African countries have also formed a number of cooperative organizations. Due to past colonial countries and chaotic border division, unrest social and political environment, the government's serious corruption, inefficient work, the chaotic judicial process, especially poor management of customs, all these leads to obstacles to foreign investment. 
Economic environment. According to the World Bank report in recent years, the growth of Africa's economy is very active, due to its GDP growth more than $4 \%$ for five consecutive years. Fig. 2 shows GDP growth rate of some important countries of Africa in 2011-2014, indicating such countries' steady growth of GDP in recent years.

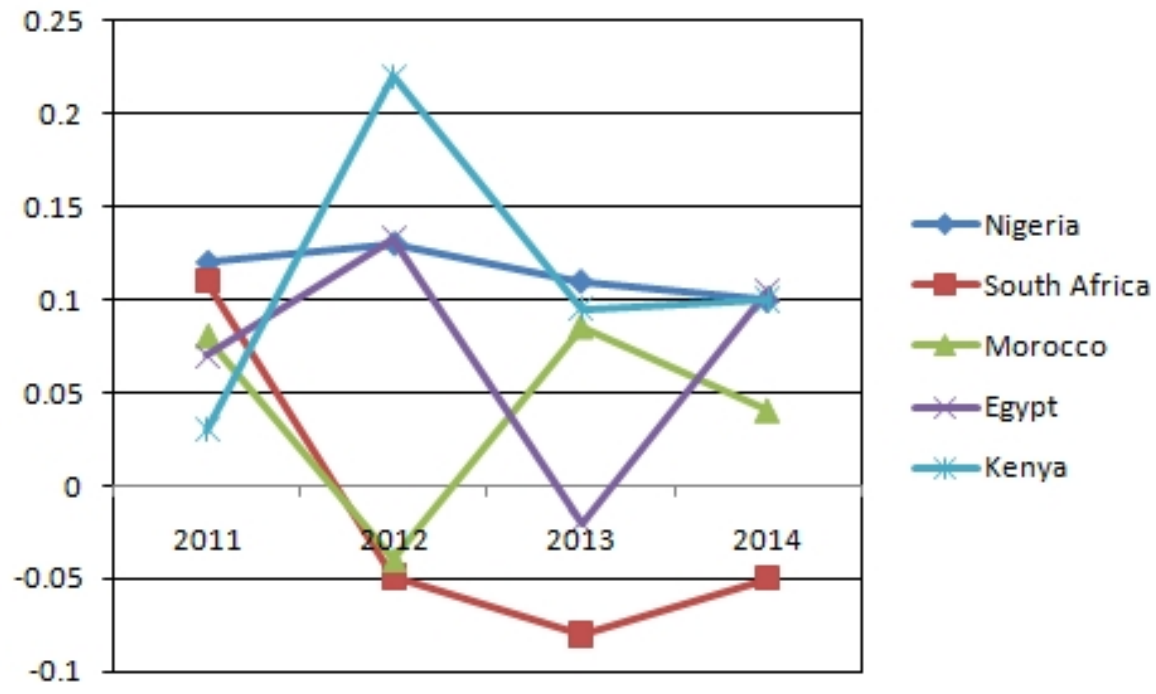

Fig 2. GDP growth rate of some important countries of Africa in 2011-2014 Data source: World Bank

\section{Technical environment.}

Infrastructure and logistics. Road transport is currently the most common way of logistics and transportation in most African countries. But only about $1 / 4$ of the highway traffic is used, so most of the electricity through the traditional motorcycle transport. Coupled with the relative lack of third-party logistics, inefficient local logistics companies, African cross-border logistics often use of international postal package, leading to long transport time, high freight and unstable.

Internet technology and other hardware factors. Africa's Internet has an increasing trend and the penetration rate is constantly improving. According to official data, in 2016, several of Africa's most developed national network coverage rate is more than $50 \%$. Especially in Kenya, network penetration reached $70 \%$, rank first in Africa. But there still is a huge space for development for the need of more professional technical staff and improved Internet infrastructure.

\section{Suggestions on Chinese enterprises in Africa to invest in e - commerce}

Government's recommendations. Pay much attention to the development of cross-border electricity providers in Africa, expand the market of Chinese-funded enterprises, and foster the cross-border development of small and medium-sized enterprises. Strengthen intergovernmental cooperation, help the local to improve infrastructure and financial services, establish information and communication equipment. Establish and improve the relevant cross-border electricity business legal policy, and promote the cooperation between customs, the Ministry of Commerce, the tax department and the inspection agency, reduce the customs process and control the supply of crossborder electricity providers. 
Enterprise's recommendations. Classify products finely, establish brand image and enhance credibility, export to Africa with comparative advantage of the goods, create their own unique positioning, focus on differentiated services to meet different needs and enhance core competitiveness. Improve the logistics system, arrange reasonable transport, establish a stable logistics team to ensure that cross-border goods for consumers, improve the international logistics information query business.

\section{Conclusions}

Based on African special political background, economic environment and technical environment, government and enterprise should take corresponding policies to promote cross-border e-commerce in Africa of Chinese enterprises.

\section{References}

[1] Z. Jin. An analysis of the current situation of China 's cross - border e-commerce development and corresponding policies under the strategy of "One Belt One Road". World Shipping, (2017), p.6. [2] A.Q. Guan. Thoughts on the development path of cross-border e-commerce under the strategy of "one way" - how to construct the dispute settlement mechanism of cross-border e-commerce. China Outsourcing, (2016), p.76. 